\title{
Impact of emotional intelligence coaching on job satisfaction of pharmacists during organizational changes
}

\author{
Nicole Seymour ${ }^{1}$, Sandy Jansen ${ }^{1}$, Lucy Feng ${ }^{1}$, Stephanie Ayres ${ }^{2}$, Zubin Austin ${ }^{3}$, Jamie A. Seabrook ${ }^{4,5}$, Philip M. \\ Jones $* 6,7$ \\ ${ }^{1}$ Department of Pharmacy, London Health Sciences Centre, London, Canada \\ ${ }^{2}$ Information Technology Services, London Health Sciences Centre, London, Canada \\ ${ }^{3}$ Leslie Dan Faculty of Pharmacy, University of Toronto, Toronto, Canada \\ ${ }^{4}$ School of Food and Nutritional Sciences, Brescia University College, Western University, London, Canada \\ ${ }^{5}$ Department of Paediatrics, Western University, London, Canada \\ ${ }^{6}$ Department of Anesthesia \& Perioperative Medicine, London Health Sciences Centre, London, Canada \\ ${ }^{7}$ Department of Epidemiology \& Biostatistics, Western University, London, Canada
}

Received: April 17, 2017

Accepted: June 21, 2017

Online Published: July 7, 2017

DOI: $10.5430 /$ jha.v6n4p39

URL: https://doi.org/10.5430/jha.v6n4p39

\begin{abstract}
Job satisfaction is known to decline during times of major organizational change and emotional intelligence has been positively correlated with job satisfaction and adaptability. Computerized provider order entry (CPOE), closed loop medication administration, electronic medication administration records and 24/7 pharmacy services were implemented at London Health Sciences Centre (LHSC) during the spring of 2014. This pilot randomized controlled trial assessed whether completion of an emotional intelligence assessment, followed by a personalized one-hour emotional intelligence coaching session, would positively impact job satisfaction stability amongst pharmacists throughout these major organizational changes. Job satisfaction was measured by the Health Professions Stress Inventory (HPSI). The primary outcome was change in HPSI score from baseline. Emotional intelligence coaching was provided to participants randomized to the intervention. Semi-structured interviews were completed at baseline and follow-up for qualitative analysis. Twenty-five participants were recruited and all participants completed the study. Job satisfaction improved in both control and intervention groups. Observations from semi-structured interviews suggested that emotional intelligence coaching may have increased self-awareness and ability to recognize dissatisfaction. Participants who were in their role for less than two years reported greater benefit from emotional intelligence coaching. Job satisfaction was worse during the anticipatory phase of major organizational change. Emotional intelligence coaching did not have an observable benefit on objective measures of job satisfaction, but it may have a subjective benefit that is more apparent in pharmacists who are less established in their role.
\end{abstract}

Key Words: Emotional intelligence, Job satisfaction, Job stress, Organizational change, Pharmacist, Pharmacy, Adaptation, Stress management

\footnotetext{
*Correspondence: Philip M. Jones; Email: philip.jones@lhsc.on.ca; Address: Rm C3-110, University Hospital- London Health Sciences Centre, 339 Windermere Rd, London, Ontario, N6A 5A5, Canada.
}

Published by Sciedu Press 


\section{INTRODUCTION}

The modern healthcare system is in a state of flux due to improvements in technology, an increased focus on patientcentered care and the ongoing need to streamline processes. Unfortunately, staff may feel powerless, ambivalent, or frustrated with the introduction of new processes. ${ }^{[1]}$ In the spring of 2014, London Health Sciences Centre (LHSC) introduced a system that included computerized provider order entry (CPOE), closed loop medication administration, electronic medication administration records, and electronic medication reconciliation (for the purposes of this study, all of these changes are referred to as CPOE). It was anticipated that CPOE would generate several perceived and actual changes for LHSC pharmacists. Layered on top of an already massive change, pharmacy services were expanded to 24 hours a day at the same time as CPOE was introduced.

According to a survey by Liu et al., ${ }^{[2]}$ the key determinants of job satisfaction amongst hospital pharmacists are degree of certainty about future employment, percentage of time spent dispensing medications, age, ability utilization and recognition. Ability utilization was the most important factor in pharmacists' perception of an ideal job. Ability utilization was defined as strong agreement with statements such as "my job is challenging", "I can use my abilities", "I can do different things", and jobs characterized by decision making authority, accomplishment, responsibility, and access to information.

The concept of emotional intelligence was introduced over a decade ago by Salovey and Mayer. It is described as "a type of social intelligence that involves the ability to monitor one's own and others' emotions, to discriminate among them, and to use this information to guide one's thinking and actions." ${ }^{[3]}$ This concept emerged from an array of research examining how people perceive, communicate with and use emotions. While several observational studies have supported the relationship between emotional intelligence and job satisfaction in medicine, nursing and dentistry, this association has not been studied with pharmacists. ${ }^{[4-8]} \mathrm{A}$ better understanding of the impact of emotional intelligence on job satisfaction amongst pharmacists may help to develop tools and educational strategies in pharmacy practice and management. Emotional intelligence has been correlated with job satisfaction, adaptability and ability to cope with stress amongst nursing students and individuals in management positions. ${ }^{[6,9]}$ Further, emotional intelligence training has been shown to improve health and well-being. ${ }^{[10]}$ The influence of emotional intelligence on adaptability and stress management may directly or indirectly relate to its impact on job satisfaction. ${ }^{[4]}$
Despite many studies suggesting that emotional intelligence and emotional intelligence coaching may have potential benefits, there are no studies examining whether emotional intelligence coaching can improve job satisfaction specifically during a highly stressful time. Since CPOE and 24/7 pharmacy were expected to negatively impact the utilization of pharmacists' abilities during the implementation phase and ability utilization has been shown to be the most important factor in pharmacists' perception of an ideal job, it was postulated that there would be a reduction in job satisfaction during the transition. This prospective pilot randomized controlled trial aimed to assess whether emotional intelligence coaching would result in greater job satisfaction stability amongst pharmacists during a major organizational change.

\section{Methods}

\subsection{Participants}

Pharmacists and pharmacy residents at LHSC's two hospital sites who were involved directly or indirectly in the drug distribution system were asked to participate. Exclusion criteria were: employment as an outpatient pharmacist or drug information pharmacist; completion of emotional intelligence coaching in the year prior to enrolment; and anticipated inability to complete the study. Possible reasons for the inability to complete the study included parental leave or planned departure from the department for any reason. The Human Subjects Research Ethics Board at Western University approved this study.

\subsection{Recruitment and randomization}

Potential participants were contacted by email. Posters were also placed in the pharmacy meeting rooms at each hospital site and an investigator (NS) presented information to potential participants during scheduled pharmacist meetings in an effort to bolster recruitment.

Participants were randomized to either the intervention or control group using a pre-specified computer-generated random number generator list that was stratified by hospital site.

\subsection{Baseline measurements}

Participants were asked to complete a baseline survey that included the Health Professions Stress Inventory (HPSI) as the primary measure for baseline job satisfaction. The HPSI is a well-known tool that has been validated amongst pharmacists in North America. ${ }^{[1,12]}$ A higher HPSI is indicative of more work-related stress; therefore, a lower score is more desirable. Participants also completed an Emotional Quotient Index (EQ-i) 2.0 assessment. The EQ-i assessment is powered by Multi-Health Systems (MHS) Incorporated and is 
recognized as a validated measure of emotional intelligence by the Consortium for Research on Emotional Intelligence in Organizations and Buros Mental Measurements Yearbook. The EQ-i is a self-reported measure to quantify several constructs related to emotional intelligence. ${ }^{[13]}$ It gives an overall emotional quotient score, as well as a score for the following five composite scales: intrapersonal, interpersonal, stress management, adaptability, and general mood. According to the Bar-On Technical Manual, the EQ-i has an internal reliability of 0.69-0.86 (alpha values), a 0.78-0.92 one-month test-retest reliability, and $0.55-0.82$ four-month test-retest reliability. ${ }^{[13,14]}$ This assessment is completed through an online proprietary program through MHS.

At baseline, all participants completed the HPSI, EQ-i assessment, and qualitative survey online. After this was complete, all participants participated in semi-structured interviews. An EQ-i coaching session was then completed by each participant randomized to the intervention group. Coaching sessions were completed one to two months prior to the introduction of CPOE and 24/7 pharmacy. Semi-structured interviews were audio recorded, transcribed and coded. Validation of coding was completed by co-authors NS and LF, who coded a minimum of three interviews in duplicate to ensure agreement. Additional categories were added if necessary. After coding consistency between NS and LF was determined to have $>90 \%$ agreement, NS completed the remainder of the coding independently. Presence or absence of themes were then tallied for each group and compared.

\subsection{Intervention}

The EQ-i tool is not designed to be used as a stand-alone or self-assessment instrument; its value is realized through a guided/facilitated coaching session with a trained individual who can help the user personalize results in a context-specific manner. All coaching sessions were approximately one hour in duration and occurred prior to introduction of CPOE and 24/7 pharmacy services. The sessions followed the Coach's Guide to an EQ-I 2.0 Debrief Session as outlined in the Workplace Report - Coach Report from MHS. The session began with a discussion about the participant's experience in taking the assessment, followed by an overview of emotional intelligence and the journey to building emotional intelligence. This was followed by a review of the results and validation of the results by the participant. Feedback included discussion of the top 3 scores identified as strengths, as well as the lowest 3 scores identified as areas for improvement. A discovery session was conducted to identify challenges to building EI and a mental rehearsal activity to establish relevance and explore benefits. The session concluded with a discussion of next steps.

\subsection{Follow-up data collection}

Participants completed a similar follow-up survey that included the HPSI. In addition, a follow-up semi-structured interview was completed by all participants within two weeks after the introduction of CPOE. The follow-up semistructured interviews were recorded, transcribed and coded as previously described.

\subsection{Outcomes}

The primary outcome of this study was change in overall job satisfaction from baseline, which was assessed using the HPSI. ${ }^{[15]}$ Change in individual categories of job satisfaction (professional recognition, patient care responsibilities, job conflicts, and professional uncertainty) from the HPSI were measured as secondary outcomes. Qualitative secondary outcomes from our pre-post online survey were change in supplemental facility-specific questions regarding job satisfaction and experience with emotional intelligence coaching. We also qualitatively examined outcomes from the semistructured interviews for any changes in positive or negative themes.

\subsection{Statistics}

Sample Size Rationale: This study aimed to enroll a convenience sample of at least 20 of 45 potentially eligible pharmacists.

Analyses: Data were analyzed using IBM SPSS Statistics, version 20.0. The mean and standard deviation were used to report continuous variables and percentages were used for categorical variables. The independent samples $t$-test was used to summarize the change in the mean job satisfaction scores between the control group and those receiving emotional intelligence coaching. A $p$-value $<.05$ was considered statistically significant.

\section{RESUlTS}

\subsection{Participants}

Twenty-five participants were enrolled in the study and none were lost to follow-up. See Figure 1 for details. Demographics are described in Table 1. Considerably more females $(n=22)$ than males $(n=3)$ participated in the study, which is representative of the male to female staffing ratio at the hospital. Participants in the control group had a higher mean EQ-i score.

\subsection{Survey results}

At baseline, there was no significant difference between the control group and treatment group HPSI job satisfaction scores (44.6+/- 9.4 vs. $39.6+/-11.5$, respectively). The change in HPSI score was $-3.9(S D=13.7)$ for the control group and $-3.2(S D=8.8)$ for the intervention group 
$(p=.28)$. This indicates an improvement in job satisfaction in both groups, with a slightly greater improvement for the control group. As seen in Table 2, scores for patient care responsibilities, job conflicts, and professional uncertainty also improved for both the control and intervention groups. Professional recognition scores worsened for both groups. No changes were statistically significant between the treatment and control groups $(p>.05)$.

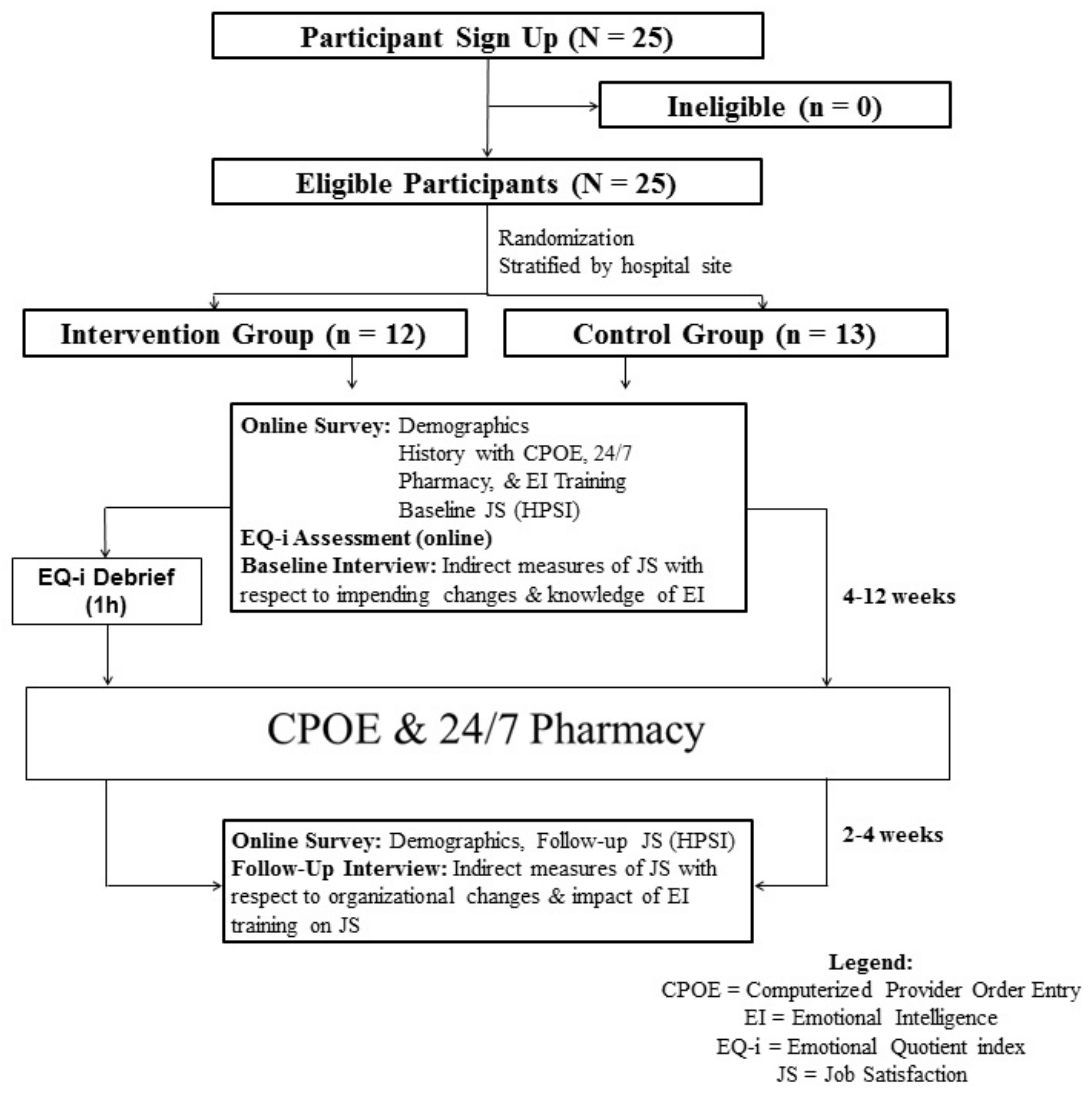

Figure 1. Eligibility and timeline of study

\subsection{Interview results}

Most participants in the intervention group reported knowing very little about emotional intelligence at baseline, whereas participants in the control group had more variable responses to this question. The majority of participants in both groups were optimistic at baseline about the potential for emotional intelligence coaching to positively impact them in some manner. The most commonly cited anticipated areas for impact were improving relations with others, stress-management and coping skill improvement, and overall self-improvement.

At follow-up, with respect to generalized statements about emotional intelligence, the control group had significantly more complaints about strain in interprofessional collaboration and generalized frustration with the actual CPOE system. Six participants in the control group and 8 participants in the intervention group specifically stated optimism that things would get better with time or that a brief period of difficulties during the learning curve was to be expected.
In all cases except for self-image, the control group had overwhelmingly more responses for anticipated benefit from emotional intelligence coaching than the intervention group reported for actual benefit. Reasons cited by the control group as anticipated benefits were improvements with stress management, adaptation skills, collaborative skills, selfawareness and conflict resolution. All but one participant in the control group wanted to complete the optional emotional intelligence coaching upon study completion.

Participants in the intervention group reported not thinking about their emotional intelligence coaching often, yet threequarters of participants in this group found the coaching to be beneficial. The intervention group most consistently reported improved self-awareness as a benefit of emotional intelligence coaching. Other benefits mentioned less frequently by the intervention group were positive reinforcement of self-image, improved stress management, development of adaptation skills, improved understanding of others, improved collaboration skills, identification of areas for self- 
improvement, and conflict resolution. Those who did not find the coaching beneficial stated that they needed longer and more frequent sessions to change behaviours.

\section{Discussion}

The current study was designed based on the assumption that job satisfaction would decrease during major organizational change. Unexpectedly, job satisfaction scores improved in both groups in all categories except professional recognition. The generalized "fear of the unknown" was common in both groups for impact of CPOE and 24/7 pharmacy on both distribution and clinical roles. The anticipatory phase of organizational change has been found to evoke feelings of diminished control and fear of the unknown. ${ }^{[16]}$ As such, a highly charged emotional state exists prior to any change that is likely to affect a worker. ${ }^{[17]}$ After the change has been implemented, the worker regains some control, as the unknown becomes known and the situation becomes manageable. Problems can be addressed and workers can break their anticipatory state and enter a more productive, less emotionally-charged phase of action. ${ }^{[16]}$ This may explain why participants in both groups had an increase in job satisfaction after implementation of CPOE and 24/7 pharmacy.

The second unexpected finding was that emotional intelligence coaching did not impact on quantitative measures of job satisfaction. Participants mentioned that they may have been affected by "the power of suggestion", stating that the mere mention of emotional intelligence may have caused them to be more emotionally intelligent and positive in their attitude.

Despite the statements being generally more negative for the intervention group at follow-up, nearly all participants in the intervention group stated that emotional intelligence coaching was beneficial to them. Participants in the intervention group indicated that although they did not generally think coaching impacted their job satisfaction or adaptability to CPOE or 24/7 pharmacy, they appreciated becoming more self-aware. One participant reflected that there was only enough coaching to realize that they were unsatisfied, but not enough coaching to learn how to fix this. Several participants echoed this and added that they gained an understanding of changes in their own behaviour when they were unhappy. The first step to changing anything is becoming aware of the problem, which is probably why most participants reported a benefit to the emotional intelligence coaching. Subjectively, individuals who were newer to their role tended to report more benefits from emotional intelligence coaching, regardless of baseline emotional intelligence score. Being in a position for longer may allow for increased confidence, comfort, and improved relationships- all of which may be postulated to improve resiliency related to change.

Table 1. Baseline demographics

\begin{tabular}{lll}
\hline & Control & Intervention \\
\hline Participants & 13 & 12 \\
Gender & 1 male & 2 males \\
& 12 females & 10 females \\
Site & 4 Site A & 4 Site A \\
& 9 Site B & 8 Site B \\
Employment & 2 part-time & - \\
& 11 full-time & 12 full-time \\
Contract & 1 temporary & 4 temporary \\
& 12 permanent & 8 permanent \\
Years on Service & 5.8 & 3.6 \\
(mean, range) & $(<1-20+)$ & $(<1-13)$ \\
Years at Hospital & 9.3 & 5.2 \\
(mean, range) & $(<1-20+)$ & $(<1-14)$ \\
Total Years as a Registered & 13.9 & 9.1 \\
Pharmacist (mean, range) & $(1-25+)$ & $(<1-25+)$ \\
History with CPOE & $1 / 13$ & $3 / 12$ \\
History with 24/7 Pharmacy & $2 / 13$ & $1 / 12$ \\
History with Overnight Shift & $2 / 13$ & $3 / 12$ \\
(any job) & & 89 \\
Mean EQ-i* Score & 95 & $(11.2)$ \\
(standard deviation) & $(14.5)$ & 39.6 \\
Mean HPSI Score & 44.6 & $(11.5)$ \\
(standard deviation) & $(9.4)$ & \\
\hline Note ${ }^{*}$ CPOE = Computerized Provider Order Entry; ${ }^{* *}$ EQ-i $=$ Emotional \\
Quotient index & & \\
& &
\end{tabular}

Table 2. Change in HPSI scores from baseline to follow-up (standard deviation, $\mathrm{N}=$ number of responders)

\begin{tabular}{lll}
\hline HPSI Category & Control $(\mathbf{N}=\mathbf{1 3})$ & Intervention $(\mathbf{N}=\mathbf{1 2})$ \\
\hline Overall & -3.889 & -3.182 \\
$(29$ questions) & $(13.7, \mathrm{~N}=9)$ & $(8.8, \mathrm{~N}=11)$ \\
Professional Recognition & 0.091 & 0.636 \\
$(8$ questions $)$ & $(4.16, \mathrm{~N}=11)$ & $(3.41, \mathrm{~N}=11)$ \\
Patient Care Responsibilities & -1.417 & -1.000 \\
(7 questions) & $(2.84, \mathrm{~N}=12)$ & $(3.44, \mathrm{~N}=12)$ \\
Job Conflicts & -1.364 & -1.417 \\
(8 questions) & $(3.41, \mathrm{~N}=11)$ & $(3.45, \mathrm{~N}=12)$ \\
Professional Uncertainty & -1.231 & -1.125 \\
$(6$ questions) & $(3.77, \mathrm{~N}=13)$ & $(3.25, \mathrm{~N}=12)$ \\
\hline
\end{tabular}


The most commonly noted limitation by the participants in this study was that the coaching was too brief. This is supported by participants stating that they rarely thought about their results. A study with managers in the United Kingdom $(n=120)$ that included once weekly full-day training sessions over four weeks failed to find differences in job stress or job satisfaction, but did show benefit in overall emotional intelligence scores and on scores for overall health and wellbeing. ${ }^{[10]}$ A study with medical students $(n=70)$ that included monthly four-hour sessions over seven months showed a benefit in emotional intelligence scores but was subject to a high drop-out rate. ${ }^{[18]}$ Another study with physicians involving 19 one-hour biweekly discussion groups to promote mindfulness, reflection, shared experience and small-group learning over 9 months elicited improved meaning and engagement in work and reduced depersonalization with sustained results at 12 months. ${ }^{[19]}$

\subsection{Strengths}

To our knowledge, this is the first randomized controlled trial to assess the impact of emotional intelligence coaching on job satisfaction specifically during a time of stress. This is also the first study to determine the impact of emotional intelligence on job satisfaction amongst pharmacists. There were no participants lost to follow-up. The data that was collected during the study offers, as individual or separate topics, the opportunity for many future studies about emotional intelligence, organizational change, and job satisfaction.

\subsection{Limitations}

Due to the nature of the intervention, blinding was not possible. Unfortunately, with a small sample size and a diverse team of pharmacists, the groups were not well balanced in factors that may affect job satisfaction or adaptation to change. There were many other potential confounders such as time of year, decreased interest in discussing CPOE due to burnout at the end of the study, and day-to-day situational or personal factors that could affect actual job satisfaction or willingness to discuss it. Reporting bias is also possible with any qualitative research, especially when the research is led by management as it was for the present study.

\section{Conclusions}

This study does not support the hypothesis that a one-hour emotional intelligence coaching session results in greater objective measures of job satisfaction amongst pharmacists during a time of major organizational change. While completion of an assessment of emotional intelligence with a one-hour coaching session may help increase awareness of one's own abilities to deal with stressful situations, it is not sufficient to bring about change in behaviour. According to subjective reporting, emotional intelligence coaching may be more beneficial for individuals who are less established in their roles. A better understanding of the impact of emotional intelligence coaching on job satisfaction may assist with the development of tools and educational efforts in pharmacy practice, change management, and departmental management overall.

\section{ACKNOWLEDGEMENTS}

The author would like to thank the following for their contributions: The Pharmacists of London Health Sciences Centre for their participation and suggestions for study design; The Joint Pharmacy Residency Board for providing direction and feedback; Lisa Rader for organizing all meetings; Sandra McKeown for her assistance with identifying background literature; Drs. Gupchuk and Wolfgang for providing support and additional information about the Health Professions Stress Inventory (HPSI); Isolina Santos and Mina Mekhail for their assistance with the ethics application; Jenn Verhoeven for providing specialized transcription services, Multi-Health Systems (MHS) for providing the Emotional Quotient Index (EQ-i) at a discounted rate; Medbuy Corporation for providing unrestricted financial support through the Research, Education, and Development Fund.

\section{FUNDING}

Medbuy Corporation is a group purchasing company and has no personal stake in the research conducted in the study. The money provided was contributed as part of an in-kind Research and Education fund. Medbuy will not profit in any way from this research. The funding provided from Medbuy was used to cover the fee for the EQ-i tests, as well as the costs of transcription services. The researchers own the data and intellectual property, and Medbuy had no access to this data or influence over its analysis or disposition.

Multi-Health Systems Inc. (MHS) provided their copyrighted web-based EQ-i 2.0 assessments at a discounted cost on the condition of receiving access to the results of the EQ-i assessments themselves, as well as a summary of the study findings. Multi-Health Systems Inc. had no access to data outside of the EQ-i, nor did they have any participation in the design, conduct, analysis, or disposition of the study.

\section{CONFlicts of InTERest Disclosure}

The authors declare they have no conflict of interest. 


\section{REFERENCES}

[1] Dowd SB, Shearer R, Davidhizar R. Helping staff cope with change. Hosp Mater Manage Q. 1998 Aug; 20(1): 23-8. PMid: 10181319.

[2] Liu CS, White L. Key determinants of hospital pharmacy staff's job satisfaction. Res Social Adm Pharm. 2011 Mar; 7(1): 51-63. PMid: 21397881. https://doi.org/10.1016/j.sapharm. 20 10.02 .003

[3] Salovey P, Brackett MA, Mayer JD. Emotional intelligence. Imagination, Cognition, \& Personality. New York, USA: Baywood Publishing Company, Inc; 1990.89 p. PMid: 2348356.

[4] Psilopanagioti A, Anagnostopoulos F, Mourtou E, et al. Emotional intelligence, emotional labor, and job satisfaction among physicians in Greece. BMC Health Serv Res. 2012 Dec 17; 12: 463, 6963-12-463.

[5] Talarico JF, Metro DG, Patel RM, et al. Emotional intelligence and its correlation to performance as a resident: A preliminary study. J Clin Anesth. 2008 Mar; 20(2): 84-9. PMid: 18410860. https ://doi.org/10.1016/j.jclinane.2007.12.008

[6] Por J, Barriball L, Fitzpatrick J, et al. Emotional intelligence: Its relationship to stress, coping, well-being and professional performance in nursing students. Nurse Educ Today. 2011 Nov; 31(8): 855-60. PMid: 21292360. https://doi.org/10.1016/j.nedt.2010.12.023

[7] Weng HC, Hung CM, Liu YT, et al. Associations between emotional intelligence and doctor burnout, job satisfaction and patient satisfaction. Med Educ. 2011 Aug; 45(8): 835-42. PMid: 21752080. https ://doi.org/10.1111/j.1365-2923.2011.03985.x

[8] Pau A, Sabri BA. Relationship between emotional intelligence and job satisfaction in newly qualified Malaysian dentists. Asia Pac J Public Health. 2012 Jun 28. PMid: 22743863.

[9] Thory K. Teaching managers to regulate their emotions better: Insights from emotional intelligence training and work-based application. Human Resource Development International. 2013; 16(1): 4-21. https://doi.org/10.1080/13678868.2012.738473

[10] Slaski M, Cartwright S. Emotional intelligence training and its implications for stress, health and performance. Stress and Health: Journal of the International Society for the Investigation of Stress. 2003; 19(4): 233-9. https ://doi.org/10.1002/smi.979
[11] Gupchup GV, Wolfgang AP. The Health Professions Stress Inventory: Factor structures for pharmacists. Percept Mot Skills. 1994 Aug; 79(1 Pt 2): 515-9. PMid: 7808890. https://doi.org/10.2466/pms . 1994.79.1.515

[12] McCann L, Hughes CM, Adair CG, et al. Assessing job satisfaction and stress among pharmacists in Northern Ireland. Pharm World Sci. 2009 Apr; 31(2): 188-94. PMid: 19132542. https : //doi.org/10.1007/s11096-008-9277-5

[13] Bar-On R. EQ-i Technical Manual. Toronto, Canada: Multi-Health Systems; 1997.

[14] Parker JD, Keefer KV, Wood LM. Toward a brief multidimensional assessment of emotional intelligence: Psychometric properties of the Emotional Quotient Inventory-Short Form. Psychol Assess. 2011 Sep; 23(3): 762-77. PMid: 21500919. https ://doi .org/10.103 $7 / \mathrm{a} 0023289$

[15] Wolfgang AP. Job stress in the health professions: A study of physicians, nurses, and pharmacists. Behav Med. 1988 Spring; 14(1): 43-7. PMid: 3365486. https://doi.org/10.1080/08964289.1988. 9935123

[16] Liu Y, Perrewe PL. Another look at the role of emotion in the organizational change: A process model. Human Resource Management Review. 2005 Dec; 15(4): 263-80. https ://doi.org/10.1016/j. hrmr.2005.12.001

[17] Fugate M, Kinicki AJ, Scheck CL. Coping with an organizational merger over four stages. Person Psychol. Win 2002; 55(4): 905-28. https://doi.org/10.1111/j.1744-6570.2002.tb00134.x

[18] Fletcher I, Leadbetter P, Curran A, et al. A pilot study assessing emotional intelligence training and communication skills with 3rd year medical students. Patient Educ Couns. 2009; 76(3): 376-9. PMid: 19674861. https://doi.org/10.1016/j.pec.2009.07.019

[19] West CP, Dyrbye LN, Rabatin JT, et al. Intervention to promote physician well-being, job satisfaction, and professionalism: A randomized clinical trial. JAMA Intern Med. 2014 Apr; 174(4): 527-33. PMid: 24515493. https ://doi.org/10.1001/jamainternmed. 2013. 14387 